\title{
The impact of frailty in aortic valve surgery
}

\author{
Elisabet Berastegui Garcia”*, Maria Luisa Camara Rosell ${ }^{1}$, Enrique Moret Ruiz², Irma Casas Garcia³
} Sara Badia Gamarra ${ }^{1}$, Claudio Fernandez Gallego ${ }^{1}$, Luis Delgado Ramis ${ }^{1}$, Ignasi Julia Almill' ${ }^{1}$ Anna Llorens Ferrer ${ }^{1}$, Bernat Romero Ferrer ${ }^{1}$, Antoni Bayes Genis ${ }^{4}$ and Christian Muñoz Guijosa ${ }^{1}$

\begin{abstract}
Background: Frailty is a geriatric syndrome that diminishes potential functional recovery after any surgical procedure. Preoperative surgical risk assessment is crucial to calibrate the risk and benefit of cardiac surgery. The aim of this study was to test usefulness of FRAIL Scale and other surgical-risk-scales and individual features of frailty in cardiac aortic valve surgery.
\end{abstract}

Methods: Prospective study. From May-2014 to February-2016, we collected 200 patients who underwent aortic valve replacement, either surgically or transcatheter. At 1-year follow-up, quality of life measurements were recorded using the EQ-5D (EuroQol). Univariate and multivariate analyses correlated preoperative condition, features of frailty and predicted risk scores with mortality, morbidity and quality of life at 1 year of follow-up.

Results: Mean age 78.2y, 56\%male. Mean-preoperative-scores: FRAIL scale 1.5(SD 1.02), STS 2.9(SD 1.13), BI 93.8(SD 7.3), ESlog I 12.8(SD 8.5) and GS $7.3 \mathrm{~s}$ (SD 1.9). Morbidity at discharge, $6 \mathrm{~m}$ and 1 year was 51, 14 and 28\%. Mortality $4 \%$. Survival at $6 \mathrm{~m} / 1$-y was $97 \%$ / 88\%. Complication-rate was higher in TAVI group due to-vascular complications. Renal dysfunction, anemia, social dependence and GS slower than $7 \mathrm{~s}$ were associated with morbidity. On multivariate analysis adjusted STS, BI and GS speed were statistically significant. Quality of life at 1-year follow-up adjusted for age and prosthesis type showed a significant association with STS and FRAIL scale scores.

Conclusions: Frailty increases surgical risk and is associated with higher morbidity. Preoperative GS slower $7 \mathrm{~s}$, and STS and FRAIL scale scores seem to be reliable predictors of quality of life at 1-year follow-up.

Keywords: Aortic valve replacement, Frailty, Risk scales

\section{Background}

Aortic stenosis (AS) is one of the most common valvular diseases in developed countries. AS is closely associated with age and its prevalence is now estimated at $12 \%$ in patients older than 75 years [1-3]. Symptomatic AS, if untreated, carries a poor prognosis [2, 3]. Medical treatment is ineffective and aortic valve replacement (AVR) is still the gold standard treatment for this condition. According to the Spanish Cardiac Surgery Association Registry [4], AVR represents $42.5 \%$ of all surgical activity

\footnotetext{
* Correspondence: eberastegui.germanstrias@gencat.cat

${ }^{1}$ Cardiac Surgery Department, Hospital Universitari Germans Trias i Pujol, Crtra Canyet s/n, 08914 Badalona, Spain

Full list of author information is available at the end of the article
}

on an isolated valve. Currently, $45 \%$ of aortic prostheses implanted in Spain are bioprostheses due to an aging population and to avoid the increased comorbidity associated with long-term anticoagulation [4-9]. The combination of this surgical activity and the increased life expectancy in developed countries in recent decades implies a high economic cost [5]. One of the current challenges for health care services is to improve quality of life (QOL) and life expectancy in an aging population with different pathologies, such as AS [9].

In recent years, various techniques have been developed to reduce the aggression of conventional surgery in a population with an already high morbidity. In particular, transcatheter aortic valve implantation (TAVI) has

(c) The Author(s). 2020 Open Access This article is licensed under a Creative Commons Attribution 4.0 International License, which permits use, sharing, adaptation, distribution and reproduction in any medium or format, as long as you give appropriate credit to the original author(s) and the source, provide a link to the Creative Commons licence, and indicate if changes were made. The images or other third party material in this article are included in the article's Creative Commons licence, unless indicated otherwise in a credit line to the material. If material is not included in the article's Creative Commons licence and your intended use is not permitted by statutory regulation or exceeds the permitted use, you will need to obtain permission directly from the copyright holder. To view a copy of this licence, visit http://creativecommons.org/licenses/by/4.0/. The Creative Commons Public Domain Dedication waiver (http://creativecommons.org/publicdomain/zero/1.0/) applies to the data made available in this article, unless otherwise stated in a credit line to the data. 
shown better outcomes than medical treatment in inoperable patients [10] and non-inferiority to conventional surgery in high-risk patients [11]. Other studies such as the SURTAVI / PARTNER III trial were designed to test the effectiveness of TAVI in intermediate-risk patients. However, they did not consider other scenarios, such as treatment of AS by minimally-invasive surgery combined with the latest generation of sutureless prostheses [12].

TAVI is no longer limited to patients considered high surgical risk but is increasingly performed in those at intermediate risk; it is therefore important to determine the most reliable tools for preoperative assessment.

In this context, frailty is an increasingly important issue. Frailty is defined as an impaired physiological response to stressors, with increased vulnerability to adverse outcomes after medical or surgical stressful conditions. Its phenotype includes weight loss, tiredness, weakness and decreased physical activity. Unfortunately, although frailty is associated with an increased risk of late mortality in patients with cardiac disease, it is not currently considered in existing surgical risk models [13, 14]. Although the prevalence of frailty increases with age, age is not the only related factor.

Gait speed (GS) defined as the time taken to walk $5 \mathrm{~m}$ - has been shown to be correlated with frailty. GS is easy to measure and does not require a geriatric specialist. Previous studies have demonstrated a relationship between slower gait and reduced survival in older patients with heart disease [13]. This suggests that risk stratification combining current risk scales with other features such as GS could improve the prediction of morbidity and mortality in this group of patients. This may in turn have a favorable impact on the short- and long-term prognosis after surgery, especially for QOL and functional capacity [15].

\section{Methods}

Single-center prospective cohort study involving patients older than 70 years who underwent elective aortic valve replacement, with follow-up assessment at 1 year. Between May 2014 and February 2016, 200 consecutive patients from a large public hospital were included (Hospital Germans Trias i Pujol, Badalona, Spain). All the patients signed an informed consent.

Data were collected preoperatively on variables related to cardiovascular health and frailty and postoperatively on immediate complications and follow-up. Inclusion criteria were age older than 70 years, and being scheduled to undergo elective TAVI or surgical AVR (with or without coronary procedure). Patients were excluded if the intervention was not elective, if they were in cardiogenic shock, had a diagnosis of endocarditis, were undergoing a redo procedure or a procedure involving ascending aortic surgery or any other concomitant procedure, if unable to attend a 1-year follow-up assessment, or if they refused to provide informed consent.

Postoperative evaluation was performed at the time of hospital discharge and at follow-up. The primary end points were all-cause mortality and in-hospital morbidity. Morbidity is defined as respiratory (intubation / tracheostomy, etc.), cardiovascular (pacemaker), infectious or renal complications, longer stay in ICU or ward (more than 2 days or 7 days).

At discharge, patients were scheduled for follow-up at 30 days, 6 months and 1 year, with clinical assessment, echocardiogram and QOL assessment with the EuroQol Group's EQ-5D questionnaire. Follow-up was completed through to the last follow-up visit for all living participants.

\section{Baseline frailty assessment}

Patient frailty was assessed using the FRAIL scale, a simple and reliable instrument that measures patients' preoperative frailty on the basis of 5 factors: Fatigue, Resistance, Ambulation, Illness and Loss of weight. Patients scoring under 3 on the scale are categorized as not frail and those scoring 3 or above, as frail.

Previous studies have measured the 5 components of the FRAIL scale in various ways. In our study, we measured resistance using the Barthel Index for activities of daily living. Published by Mahoney and Barthel in 1965, the Barthel Index is the instrument recommended by the British Gerontology Society to evaluate the ability of elderly patients to independently perform basic activities of daily living. It yields a score between 0 and 100. The preoperative nutritional status of patients was evaluated using serum albumin level and body muscle-mass index. Strength was measured using a hand grip dynamometer. Fatigue and ambulation were measured with a 5-m gaitspeed test. All measures for frailty were taken by a single therapist.

\section{Surgical treatment}

The prostheses used in this study included:

- TAVI: In these cases it is a trivalve biological prosthesis, of porcine pericardium, mounted and sutured on a self-expanding nitinol structure.

- Stented- biological: Bovine pericardial tissue. They are recommended in patients who do not wish to take anticoagulants, since they have very little tendency to form embolisms or thrombosis even without anticoagulants.

- Sutureless: Sutureless prostheses are composed of a nitinol structure and a biological prosthesis of bovine pericardium. In our series, it is a bioprosthesis composed of a bovine pericardium valve mounted on a NITINOL self-expanding double ring stent; and a vertical structure covered with 
Carbofilm. The malleable properties of nitinol makes the stent adapt to the anatomy of the root aorta reducing the stress load on the leaflets.

\section{Postoperative assessment}

Postoperative evaluation was performed at the time of hospital discharge and at follow-up. The primary end points were all-cause mortality and in-hospital morbidity defined by length of hospital stay, respiratory, renal, vascular or neurological complications; and QOL at 1-year follow-up was a secondary end point. The number and causes of death or postoperative re hospitalizations prior to follow-up were obtained from clinical records stored in public health systems shared database.

QOL was assessed at baseline and 1-year follow-up using the Spanish version of the widely-used EQ-5D, which has been prospectively validated in Spain. The EQ-5D consists of questions covering 5 areas, namely mobility, self-care, usual activities, pain/discomfort and anxiety/depression, each yielding a score from 1 (no limitation) to 3 (extreme limitation), and a visual analog scale, with 0 indicating "the worst health you can imagine" and 100 "the best health you can imagine".

All patients gave consent to participate, and the study was approved by the hospital's institutional ethics committee in accordance with accepted ethical standards.

\section{Statistical analyses}

Categorical variables were expressed as frequencies and percentages. Continuous variables were described as means \pm SD or as medians and 25th and 75th percentils. Chi-square, Fisher or ANOVA tests were used to compare preoperative, intraoperative and postoperative patient characteristics; a separate analysis was performed for each treatment group (prosthesis type). QOL was analyzed using ANOVA or the Kruskal-Wallis test, also separately for each prosthesis type. The multivariate analysis of morbidity and mortality risk factors was performed using a multivariate binary logistic regression model with the statistically significant variable detected in the univariate analysis. The level of significance was set at $p<0.5$ required to claim significance. Final validation of the model was carried out through discrimination and calibration with ROC curves. ROC curves were used to evaluate frailty scores, their relation to other risk scores and their predictive capacity for morbidity. Curves for the different prosthesis groups were compared using a log-rank test. All statistical analyses were performed with SPSS 15 (SPSS Inc.).

\section{Results}

The average age was 75 years for all treatment groups. Only 8 patients received a concomitant coronary procedure.
Breakdown according to the type of prosthesis was 22 TAVI, 80 stented valves and 98 sutureless valves. $92.5 \%$ of patients had hypertension, $31 \%$ had diabetes, $64 \%$ had dyslipidemia and $32 \%$ had chronic obstructive pulmonary disease (COPD). Up to $30 \%$ of the patients had a diagnosis of peripheral arterial disease at the time of surgery. The TAVI group had a higher percentage of preoperative renal insufficiency, social dependence, preprocedure hospital admissions, anemia and hypoalbuminemia (Table 1).

Concerning features of frailty, the TAVI and sutureless groups obtained higher scores on the risk scales and worse scores for dependency or Barthel Index than the stented group. The results of the GS and strength test (handgrip) are shown in Table 2.

The intraoperative characteristics are shown in Table 3.

Only the stented and sutureless groups were comparable in terms of use of extracorporeal circulation. For both these groups, the rate of immediate complications was close $43 \%$ - defined as the occurrence of any respiratory event, prolonged intubation, infectious or vascular complication, deterioration of renal function or neurological event (Table 4).

By follow-up at 1 year, the occurrence of complications and re-admissions was at $14-29 \%$ respectively the most frequent complications being respiratory or exacerbation of renal disease or heart failure. The TAVI group had more vascular and neurological complications than SAVR groups.

Mortality was $4 \%$ (8 patients) at discharge, $2.6 \%$ at 6 months and $12.6 \%$ at 1 year, with no differences between groups (Fig. 1). The main cause of death in the followup period was progression of chronic disease (heart failure and pulmonary disease) followed by oncological disease. $2.6 \%$ of patients were diagnosed with a de novo oncological process, with $80 \%$ mortality at 1 -year followup in this group.

In the univariate analysis, only preoperative anemia, arterial disease, renal insufficiency, GS $>7 \mathrm{~s}$, Barthel Index and STS score were significant predictors of morbidity. Adjusted for prosthesis type and age, in the multivariate analysis, these were reduced to only Barthel Index, GS $>7 \mathrm{~s}$, and STS score. Adjusted for patient characteristics, only gait speed, FRAIL score and STS score showed a significant relationship between preoperative values and improvement in QOL at 1-year follow-up (Tables 5 and 6).

An ROC study showed that the multivariate analysis with morbidity was superior to the univariate analysis for any individual feature and morbidity (Fig. 2).

\section{Discussion}

AS is the third most frequent cardiovascular disease in the Western world, where its prevalence is around 18\% 
Table 1 Preoperative features

\begin{tabular}{|c|c|c|c|c|c|}
\hline Preoperative features & Stent ED \% (n) 40\% (80) & Sutureless \%(n) 49\% (98) & Tavi \%(n) 11\% (22) & Total 200 & $\mathrm{p}$ \\
\hline Age (SD) & $76.6(3.9)$ & $78.5(3.9)$ & 79.8(7.0) & $78.25(4.6)$ & .08 \\
\hline BMI (SD) & 28.1(3.6) & $28.6(4.6)$ & $30.4(8,0)$ & $28.65(4.8)$ & .07 \\
\hline Gender(Male/Female) & $65 \%(52) 35 \%(28)$ & $46 \%(45) 54 \%(53)$ & $68 \%(15) 32(7)$ & $112(56) 88(44)$ & .06 \\
\hline HTA \% (n) & $97.5 \%(78)$ & $89.8 \%(88)$ & $86.4 \%(19)$ & $92.5(185)$ & .07 \\
\hline $\begin{array}{l}\text { DM \% (n). } \\
\text { (ADOS/Insulina) }\end{array}$ & $32.5(26)$ & $19.4(19)$ & $77.3 \%(17)$ & $31 \%(62)$ & .08 \\
\hline DLP \% (n) & $67.5 \%(54)$ & $58.4 \%(57)$ & $77.3 \%(17)$ & $64 \%(128)$ & .1 \\
\hline Arteriopatía \% (n) & $20 \%(16)$ & $30.6 \%(30)$ & $63.6 \%(14)$ & $30 \%(60)$ & .9 \\
\hline Liver Disease \%(n) & $1.3 \%(1)$ & $2 \%(2)$ & $4,5 \%(1)$ & $4 \%(2)$ & .8 \\
\hline COPD \%(n) & $27.5 \%(22)$ & $29.6 \%(29)$ & $59.1 \%(13)$ & $32 \%(64)$ & .8 \\
\hline CRF \%(n) & $12.5 \%(10)$ & $16.3 \%(16)$ & $27.3 \%(6)$ & $16 \%(32)$ & .6 \\
\hline Social dependence & $6.3 \%(5)$ & $17.3 \%(17)$ & $59.1 \%(13)$ & $17.5 \%(35)$ & .06 \\
\hline Preop. Income & $51.2 \%(41)$ & $51 \%(50)$ & $95.5 \%(21)$ & $56 \%(112)$ & .07 \\
\hline Anemia $<34 \%$ & $23.8 \%(19)$ & $19.4 \%(19)$ & $72 \%(16)$ & $27 \%(54)$ & .06 \\
\hline Albúmin $<34 \mathrm{~g} / \mathrm{l}$ & $8.8 \%(7)$ & $8.2 \%(8)$ & $31.8 \%(7)$ & $11 \%(22)$ & .08 \\
\hline Depression treatment $\%(n)$ & $6.3 \%(5)$ & $12.2 \%(12)$ & $9.1 \%(2)$ & $9.5 \%(19)$ & .09 \\
\hline
\end{tabular}

SD Standard Desviation

$B M I$ Body mass index HTA High blood pressure, DM Diabetes mellitus (ADOs oral treatment), DLP Dyslipidemia, COPD (Chronic obstructive pulmonar disease), enfermedad pulmonar obstructiva crónica), CRF Chronic renal failure

T-Student. p .05

in the octogenarian population $[1,2]$. Aortic valve replacement is currently the only definitive treatment for patients with AS, showing good long-term outcomes even for populations at high and intermediate risk [16, 17]. Preoperative estimation of surgical risk is essential during the therapeutic decision-making process. Current risk models are based on demographic and clinical factors, and other measurable factors of comorbidity, but do not include a comprehensive assessment of frailty, which is known to affect morbidity and mortality.

Table 2 Frailty features and risk scores

\begin{tabular}{llllll}
\hline & $\begin{array}{l}\text { Stented } \\
(80)\end{array}$ & $\begin{array}{l}\text { Sutureless } \\
(98)\end{array}$ & $\begin{array}{l}\text { TAVR } \\
(22)\end{array}$ & $\begin{array}{l}\text { Total } \\
(200)\end{array}$ & P \\
\hline Age & $76.2(3.9)$ & $79.5(3.9)$ & $79.8(7)$ & $78.2(4.6)$ & .06 \\
\hline $\begin{array}{l}\text { Barthel } \\
\text { Index }\end{array}$ & $\begin{array}{l}93.93 \\
(8.3)\end{array}$ & $93.3(7.4)$ & $92(7.9)$ & $93.8(7.8)$ & .07 \\
\hline $\begin{array}{l}\text { EuroS } \\
\text { core } \\
\text { log }\end{array}$ & $10.8(7.2)$ & $14.6(5.4)$ & $12(8.8)$ & $12.8(38.5)$ & .05 \\
\hline $\begin{array}{l}\text { STS } \\
\text { Gait }\end{array}$ & $2.78(1)$ & $2.9(1.11)$ & $3.4(1.54)$ & $2.9(1.13)$ & \\
\hline $\begin{array}{l}\text { Hand } \\
\text { grip }\end{array}$ & $7.4(2.3)$ & $7.5(1.66)$ & $7.8(1.9)$ & $7.3(1.9)$ & .04 \\
\hline $\begin{array}{l}\text { FRAlL } \\
\text { scale }\end{array}$ & $18.8(7.1)$ & $19.3(8.6)$ & $19(7.9)$ & $19.2(8)$ \\
\hline
\end{tabular}


Table 3 Surgical data

\begin{tabular}{|c|c|c|c|c|c|}
\hline & Stented & Sutureless & TAVI & Total & p \\
\hline ECC & $83.4(32)$ & $69.4(23.27)$ & 0 & $67.4(36)$ & .08 \\
\hline Ischemia & $63.8(23.8)$ & $48.17(15.5)$ & 0 & $49.13(26)$ & .04 \\
\hline $\begin{array}{l}\text { Surgical time } \\
\text { (min) }\end{array}$ & 165 (25) & $118(28)$ & $170(20)$ & $125(32)$ & .07 \\
\hline ETI (h) & $8.2(12)$ & $5.3(5.1)$ & $3(9.1)$ & $6.6(9.3)$ & .003 \\
\hline ETD & $269(180)$ & $289(170)$ & 0 & 279 (184) & .08 \\
\hline $\begin{array}{l}\text { ICU } \\
\text { (days) }\end{array}$ & $3(5.5)$ & $3.5(7.5)$ & $2.4(2.5)$ & $3.1(6.4)$ & .61 \\
\hline $\begin{array}{l}\text { Hospitalization } \\
\text { (days) }\end{array}$ & $12(7.7)$ & $13(9.0)$ & $14(11)$ & $12.8(8.8)$ & .12 \\
\hline
\end{tabular}

ECC Extracorporeal circulation time, ETD Endothoracic drainage, ETI Endotracheal intubation (oral), $h$ Hours, ICU Intensive care unit, min Minutes, TAVR Transcatheter aortic valve replacement

Table 4 Postoperative complications

\begin{tabular}{|c|c|c|c|c|c|}
\hline$\%(\mathrm{~N})$ & Stented (80) & $\begin{array}{l}\text { Sutureless } \\
(98)\end{array}$ & $\begin{array}{l}\text { TAVR } \\
\text { (22) }\end{array}$ & Total & p \\
\hline Respiratory & $\begin{array}{l}10 \% \\
(8)\end{array}$ & $9.2 \%(9)$ & $\begin{array}{l}13.6 \% \\
\text { (3) }\end{array}$ & $\begin{array}{l}10 \% \\
(20)\end{array}$ & .828 \\
\hline Infectious & $12.5 \%(10)$ & $12.2 \%(11)$ & $\begin{array}{l}54.5 \% \\
(12)\end{array}$ & $17 \%(34)$ & .001 \\
\hline Vascular & 0 & 0 & $\begin{array}{l}62 \% \\
(14)\end{array}$ & $7 \%(14)$ & .05 \\
\hline Pacemaker & $\begin{array}{l}8.8 \% \\
(7)\end{array}$ & $8.2 \%(8)$ & $\begin{array}{l}13.6 \% \\
\text { (3) }\end{array}$ & $\begin{array}{l}9 \% \\
(18)\end{array}$ & .67 \\
\hline $\begin{array}{l}\text { Kidney } \\
\text { failure }\end{array}$ & $\begin{array}{l}5 \% \\
(4)\end{array}$ & $\begin{array}{l}13.3 \% \\
(13)\end{array}$ & $\begin{array}{l}9.1 \% \\
\text { (2) }\end{array}$ & $\begin{array}{l}9.5 \% \\
(19)\end{array}$ & .17 \\
\hline Neurological & $1.3 \%(1)$ & $6.1 \%(5)$ & $\begin{array}{l}4.5 \% \\
\text { (2) }\end{array}$ & $4 \%(8)$ & .124 \\
\hline
\end{tabular}




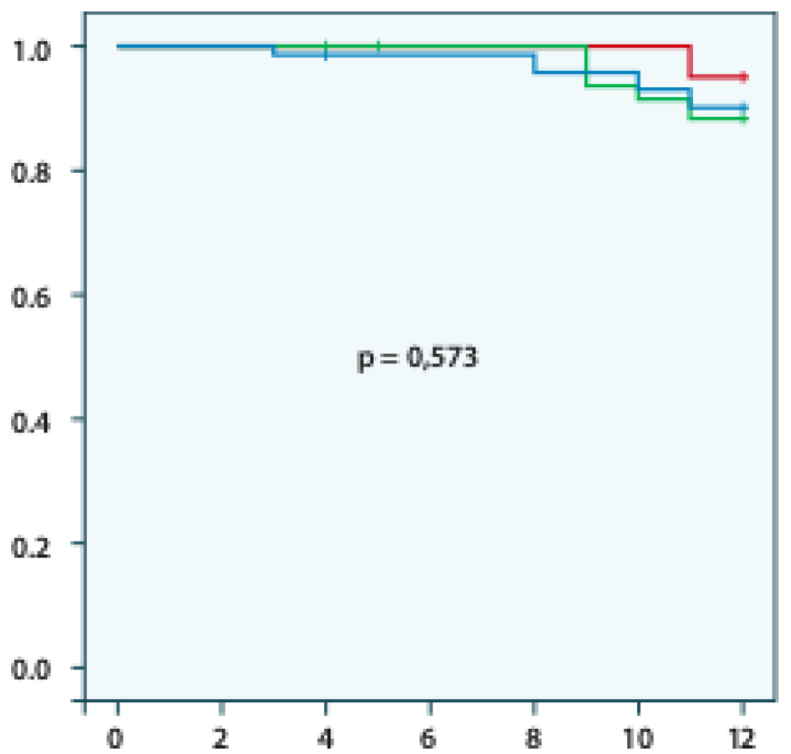

1. Stented ( $B L U E)$

2. Sutureless ( GREEN)

3. TAVI - RED

Fig. 1 Kaplan Meier

The potential impact of a procedure on a patient's long-term QOL must also be considered when selecting one surgical procedure over another. Preoperative measures of frailty appear to be predictive of postoperative QOL [18-20].

In the present prospective study, 200 patients undergoing aortic valve replacement were divided into 3 groups according to AVR surgical procedure. The study population was homogenous in terms of preoperative predictors of cardiovascular risk, but the TAVI group showed higher preoperative rates of peripheral arterial disease, kidney disease, hypoalbuminemia, anemia and preoperative admission rate. The sutureless and TAVI groups had higher scores for risk (STS) and frailty (FRAIL scale) than the stented prosthesis group. Overall survival at discharge, 6 months and 1 year was 96, 97 and 89\% respectively. At 1-year follow-up 26 patients had died.

Our results on preoperative features are similar to those reported in the European Cardiac Surgery Registry for stented/sutureless prosthesis implantation surgery in intermediate- to high-risk populations [21] and in the Spanish Cardiac Surgery Registry for TAVI. Mortality rates at 6 months and 1 year were 2.6 and $11 \%$, respectively, similar to other previously published series. However, the 4\% 30-day mortality, was lower than that reported in various TAVI registries (Spanish, Canadian, French, British, Italian and German), which ranges between 8 and $10 \%$ and $16-24 \% /$ year $[4,21-24]$.
The rate of postoperative complications was highest in the TAVI group, when compared to the SAVR group and higher than that described in other TAVI registries. This was mainly due to vascular and infectious complications, which may have been related to the high rate of peripheral vascular disease and transfemoral approach.

Complications during the follow-up period were related to the patients' preoperative condition and comorbidities. Respiratory complications or cardiac failure occurred in over $8 \%$ of patients at 6 months and 18.2 to $23 \%$ at 1 year. The leading cause of death was progression of respiratory or renal disease, and the second was oncological disease.

\section{Preoperative factors related to morbidity and mortality}

As in other studies, our univariate analysis found that arterial disease, anemia, STS score, Barthel Index and gait speed were associated with morbidity. After adjusting for age, only STS score, Barthel Index and gait speed were significant. Aging generally involves a decrease in muscular strength, related to loss of muscle mass and protein reduction, a factor measured by handgrip, although no association with morbidity was found [13, 14, 25, 26].

GS is an easily measured patient feature and has been shown to correlate with complications in patients with heart failure and cardiac surgery [13]. It is a useful tool for predicting morbidity in elderly patients and has been shown to be related to resilience. This association not only has clinical implications, but also has a bearing on 
Table 5 Univariate Analysis

\begin{tabular}{|c|c|c|c|}
\hline & $\begin{array}{l}\text { No complications, } \\
\text { ( } n=102 \text { patients) }\end{array}$ & $\begin{array}{l}\text { Complications } \\
\text { ( } n=98 \text { patients) }\end{array}$ & p \\
\hline Age & $77.9(4.9)$ & $78.5(4.4)$ & .224 \\
\hline Anemia & $>3280.3 \%(82)$ & $>3265.3 \%(64)$ & .012 \\
\hline$\%(n)$ & $<3219.6 \%(20)$ & $<3234.6 \%(34)$ & \\
\hline $\begin{array}{l}\text { Albumin } \\
\% \text { (n) }\end{array}$ & $\begin{array}{l}>3491.1 \%(93) \\
<348.8 \%(9)\end{array}$ & $\begin{array}{l}>34 \quad 86.7 \%(85) \\
<3413.2 \%(13)\end{array}$ & .223 \\
\hline $\begin{array}{ll}\text { Gait speed, } & \text { sec, mean } \\
\text { (SD) } & \end{array}$ & $6.2(1.2)$ & $8.5(1.9)$ & .001 \\
\hline $\begin{array}{l}\% \text { patients (n) } \\
\geq 7 \text { seg }\end{array}$ & $303 \%(31)$ & $96.93 \%$ (95) & \\
\hline $\begin{array}{l}\text { Barthel } \\
\text { (SD) }\end{array}$ & $95.19(6.7)$ & $92.3(8.5)$ & .005 \\
\hline $\begin{array}{l}\text { FRAll score } \\
\text { (SD) }\end{array}$ & $1.4(1.04)$ & $1.5(1.01)$ & .82 \\
\hline $\begin{array}{l}\text { Handgrip } \\
\text { (SD) }\end{array}$ & $20.14(8.1)$ & $18.29(7.8)$ & .85 \\
\hline $\begin{array}{l}\text { Depression } \\
\text { treatment } \\
\% \text { (n) }\end{array}$ & $11.7 \%$ & $7.1 \%$ & .224 \\
\hline $\begin{array}{l}\text { Euroscore } \\
\log \\
\text { (SD) }\end{array}$ & $10.13(53)$ & $15.11(72)$ & .14 \\
\hline $\begin{array}{l}\text { STS score } \\
\text { (SD) }\end{array}$ & $2.7(0.9)$ & $3.05(1.2)$ & .004 \\
\hline
\end{tabular}

\begin{tabular}{l|l|l|l}
\hline & $\begin{array}{l}\text { No complications } \\
(n-102)\end{array}$ & $\begin{array}{l}\text { Complications } \\
(n-98)\end{array}$ & P \\
\hline $\begin{array}{l}\text { Gender \% (n) } \\
\text { male/female }\end{array}$ & $\begin{array}{l}53.2 \%(55) \\
46.97 \%(47)\end{array}$ & $\begin{array}{l}58.1(57) \\
41.8(41)\end{array}$ & .322 \\
\hline HTN \% (n) & $92.1 \%(94)$ & $92.85 \%(91)$ & .53 \\
\hline DM \% (n) & $26.4 \%(27)$ & $35.7 \%(35)$ & .104 \\
\hline DLP \% (n) & $627 \%(64)$ & $65.5 \%(64)$ & .409 \\
\hline
\end{tabular}

\begin{tabular}{l|l|l|l|}
\hline $\begin{array}{l}\text { Arterial disease \% } \\
\text { (n) }\end{array}$ & $24.5 \%(25)$ & $35.7 \%(35)$ & .05 \\
\hline Liver disease \% (n) & $2.9 \%(3)$ & $1.02 \%(1)$ & .326 \\
\hline COPD \% (n) & $27.4 \%(28)$ & $36.4 \%(36)$ & .49 \\
\hline CRF \% (n) & $10.7 \%(11)$ & $21.4 \%(21)$ & .03 \\
\hline $\begin{array}{l}\text { Social dependonce } \\
\%(n)\end{array}$ & $12.7 \%(13)$ & $22.4 \%(22)$ & .05 \\
\hline $\begin{array}{l}\text { Preoperative } \\
\text { hospital admission } \\
\% \text { (n) }\end{array}$ & $52.9 \%(54)$ & $59.1 \%(58)$ & .22 \\
\hline
\end{tabular}

COPD Chronic obstructive pulmonary disease, CRF Chronic renal failure, DM Diabetes mellitus, DLP Dyslipidemia, HTN Hypertension Univariate. T. Student p.05 
Table 6 Multivariate analysis. Factors predictive of morbidity in cardiac surgery

\begin{tabular}{|llll|}
\hline & $\mathbf{p}$ & ExpB & $95 \% \mathrm{Cl}$ \\
\hline Arterial disease & .097 & & \\
\hline CRF & .83 & & $(.90 ; 1.016)$ \\
\hline Barthel Index & .011 & .96 & \\
\hline EuroScore log & .13 & & $(1.004 ; 2.29)$ \\
\hline STS score & .05 & 1.39 & $(30.82 ; 571.0)$ \\
\hline Gait speed & .015 & 4.13 & \\
\hline Anemia & .68 & & \\
\hline
\end{tabular}

CRF: chronic renal failure; STS: Society of Thoracic Surgeons

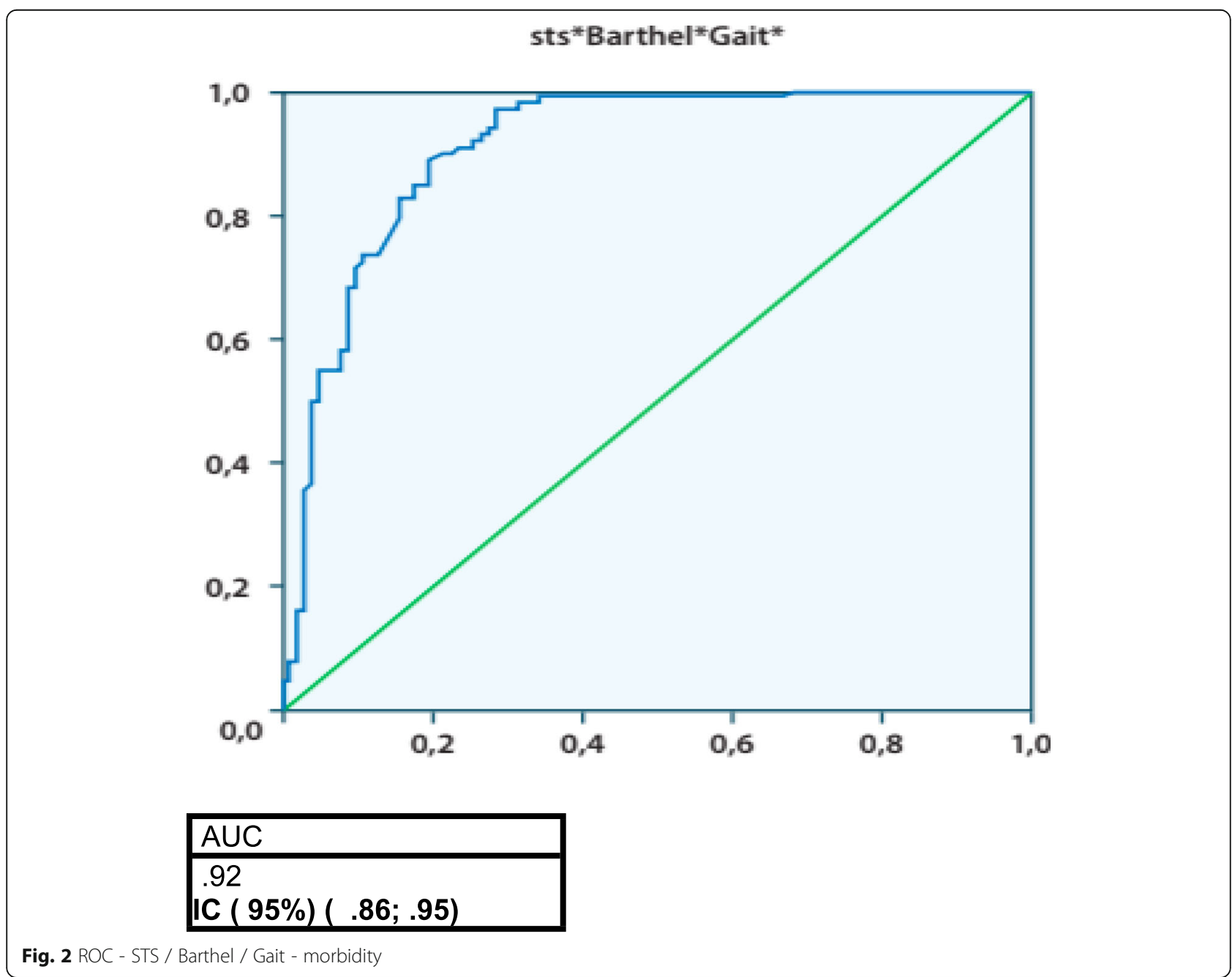


long-term quality of life. In addition, there is also an overall economic impact to consider, which should take into account not only direct costs but also indirect costs incurred due to intraoperative and postoperative complications.

To date, gait speed has been used as an isolated parameter. In our study, gait speed combined with STS and Barthel score increased its predictive capacity for morbidity.

\section{Quality of life at follow-up}

Frailty increases surgical risk. Some studies have found that even with less invasive techniques, QOL outcomes are not necessarily improved in intermediate- to highrisk patients. One of the most widely-used and validated scales for measuring QOL in our setting is the EQ-5D which assesses patients' physical and psychological condition [27, 28]. In contrast to what is reported in other studies, the TAVI group in our study had a worse QOL at 1 year than those who had received a conventional or sutureless prosthesis. Furthermore, as in other studies, TAVI patients also reported a worse QOL in items related to their affective or psychological wellbeing, not just in the functional-motor sphere [29].

Some previous studies have found an association between preoperative factors such as peripheral arterial disease and mood and worse QOL. Nevertheless, there are no studies that assess the association between preoperative risk factors or frailty features with QOL at follow-up. In our univariate analysis, faster gait speed and higher STS and FRAIL scale scores were negatively correlated with QOL at 1-year follow-up, but in multivariate analysis of these 3 factors only STS and FRAIL score remained predictors of worse QOL [30].

Thus, regardless of the surgical procedure employed, only STS and FRAIL score were strong predictors of QOL at 1-year follow-up. The importance of this conclusion becomes evident on analysis of the individual prosthesis types: although in our study there were relatively few TAVI interventions compared with stented or sutureless valve replacements, TAVI did not appear to be associated with improved QOL. It is therefore important to emphasize that the use of risk and frailty scales improves the prediction of morbidity and, most importantly, quality of life long term.

\section{Conclusions}

The combination of STS score, Barthel Index and gait speed appears to have considerable predictive power for morbidity. In addition, we have shown that preoperative frailty assessment is a useful predictor of patient quality of life at 1-year follow-up. It is important to know which patients will benefit from which types of prosthesis to reduce immediate morbidity and to improve clinicians' confidence regarding the quality of life that we can afford our patients.

\section{Abbreviations}

AS: Aortic stenosis; AVR: Aortic Valve replacement; BI: Index Barthel; COPD: Chronic Obstructive pulmonary Disease; EQ 5D: Euro Quol Test; GS: Gait Speed; QuOl: Quality of life; STS: Society Thoracic Surgeons;

TAVI: Transcatheter Aortic valve implantation

\section{Acknowledgements}

The author thank the members of Anesthesiology Department, Cardiology and Intensive Care Unit Department for their role in taking care of the patients and collaborate with the study.

\section{Authors' contributions}

All authors contributed to perform the surgerys. MLC: Codirector Thesis. EMR: Codirector Thesis. IGC: Codirector Thesis. SB: Perform Surgeries. CF: Perform Surgeries. LD: Recruit patients. IJ: Perform Surgeries. ALI: Recruit and follow up patients. BR: Recruit patients. AB: Stadistical support. CMG: Supoort writting. The signing author develop the structure of work, recruit patients and follow up on them. The author(s) read and approved the final manuscript.

\section{Funding}

Not applicable.

\section{Availability of data and materials}

- Right to privacy and informed consent. The authors have obtained the informed consent of the patients and / or subjects referred to in the article - The datasets generated and/or analysed during the current study are available in the Tesis Doctorals en XArxa (TDX) repository, http://hdl.handle. net/10803/461594.

\section{Ethics approval and consent to participate}

Before the study started, the project was evaluated by the Center's Research Ethics Committee, obtaining the pertinent authorizations from the center's managers. The following study achieved the CEICH. Comite d'Ėtica d' Investigació mèdica H. Germans Trias i Pujol approval certificate - May 2014. Certificate number P1-14-046.

All the patients has a signed written informed consent.

\section{Consent for publication}

Not applicable.

\section{Competing interests}

The authors declare that there is no potential conflict of interest related to the article.

\section{Author details \\ ${ }^{1}$ Cardiac Surgery Department, Hospital Universitari Germans Trias i Pujol, Crtra Canyet s/n, 08914 Badalona, Spain. ${ }^{2}$ Anesthesiology Department, Hospital Universitari Germans Trias i Pujol, Badalona, Spain. ${ }^{3}$ Preventive Medicine Department, Hospital Universitari Germans Trias i Pujol, Badalona, Spain. ${ }^{4}$ Cardiovascular Institut, Hospital Universitari Germans Trias I Pujol, Badalona, Spain.}

Received: 30 March 2020 Accepted: 18 August 2020

Published online: 27 October 2020

\section{References}

1. Osnabrugge RLJ, Mylotte D, Head SJ, et al. Aortic stenosis in the elderly: disease prevalence and number of candidates for transcatheter aortic valve replacement:a meta analysis and modeling study. J Am Coll Cardiol. 2013; 62:1002-12.

2. Lung B, Vahanian A. Epidemiology of valvular heart disease in the adult. Nat Rev Cardiol. 2011;8:162-72.

3. Bonow RO, Carabello BA, Chatterjee $\mathrm{K}$ et al. Guidelines for the management of patients with valvular heart disease. ACC/AHA 2006.

4. Bustamante-Munguira J, Centella T, Polo L, et al. Cirugía cardiovascular en España en el año 2014. Registro de intervenciones de la Sociedad Española de Cirugía Torácica-Cardiovascular. Cirugía Cardiovascular. 2015;22(6):297313.

5. Fried LP, Tangen CM, Walston J, et al. Frailty in older adults: evidence for a phenotype. J Gerontol Ser A Biol Med Sci. 2001;56(3):M146-57. 
6. Rockwood K, et al. Frailty defined by deficit accumulation and GeriatricMedicine defined by frailty. Clin Geriatr Med. 2011;21:1-17.

7. Passik CS, Ackermann DM, Pluth JR, et al. Temporal changes in the causes of aortic stenosis: a surgical pathologic study of 646 cases. Mayo Clin Proc 1987:62:119-23.

8. Catalina María Martínez Ochoaa,*, Eliana Mabel Cañasa, Jorge Alberto Castro Pérez, et al. Valor predictive del EuroScore II y el STS score en pacients sometidos a cirugia cardiac valvular por el abordaje minimamente invasive. Rev Colomb Cardiol. 2016;23(5):427-34.

9. Fulop T, Larbi A, Witkowski JM, et al. Aging, frailty and age-related diseases. Biogerontology. 2010;10(5):547-63.

10. León MB, Smith CR, Mack M, Miller DC, Moses JW, Svensson LG. et ál. Transcatheter aortic-valve implantation for aortic stenosis in patients who cannot undergo surgery. N Engl J Med. 2010;363(17):1597-607.21.

11. Smith CR, Leon MB, Mack MJ. et ál. Transcatheter versus surgical aortic-valve replacement in high-risk patients. N Engl J Med. 2011;364(23):2187-98.

12. Reardon MJ, Van Mieghem NM, et al. SURTAVI investigators. Surgical or Transcatheter aortic-valve replacement in intermediate-risk patients. N Engl J Med. 2017;376(14):1321-31.

13. Afilalo J, Lauck S, Hyun Kim D, et al. Frailty assessment in older adults undergoing transcatheter or surgical aortic valve replacement: the frailtyAVR study. J Am Coll Cardiol. 2016;67(13):8.

14. Nashef SAM, Roques F, Michel P, et al. European system for cardiac operative risk evaluation (EuroSCORE). Eur J Cardiothorac Surg. 1999; 16(1):9-13.

15. Dimarakis I, Rehman SM, Grant SW, et al. Conventional aortic valve replacement for high-risk aortic stenosis patients not suitable for transcatheter aortic valve implantation: feasibility and outcome. Eur J Cardiothorac Surg. 2011;40(3):743-8.

16. Folliguet T, Dibie A, Laborde F, et al. Future of cardiac surgery: minimally invasive techniques in sutureless valve resection. Futur Cardiol. 2009;5(5): 443-52.

17. Dewey TM, Brown D, Ryan WH, et al. Reliability of risk algorithms in predicting early and late operative outcomes in high-risk patients undergoing aortic valve replacement. J Thorac Cardiovasc Surg. 2008;135(1): 180-7.

18. Ferrari S, Ciuca C, Grisoglio E, Claudia T, et al. Quality of life after transcatheter aortic valve implantation: a Comprehensive literature review and critical appraisal. G Ital Cardiol ( Rome ). 2016;17(12 Suppl):5S-14..

19. Prudon I, Noyez L, VAN Swieten H, Scheffer GJ. Is gait speed improving performance of the EuroSCORE II for prediction of early mortality and major morbidity in the elderly? J Cardiovasc Surg. 2016;57(4):592-7 Epub 2014 May 13.

20. Carnero-Alcázar M, Maroto LC, Cobiella-Carnicer J, et al. Transcatheter versus surgical aortic valve replacement in moderate and high-risk patients: a meta-analysis. Eur J Cardiothorac Surg. 2017;51(4):644-52.

21. Shrestha M, Fischlein T, Meuris $B$, et al. European multicentre experience with the sutureless Perceval valve: clinical and haemodynamic outcomes up to 5 years in over 700 patients. Eur J Cardiothorac Surg. 2016;49(1): 234-41

22. Moat NE, Ludman P, De Belder MA, et al. Long-term outcomes after transcatheter aortic valve implantation in high-risk patients with severe aortic stenosis: the U.K. TAVI (United Kingdom transcatheter aortic valve implantation) registry. J Am Coll Cardiol. 2011;58(20):2130-8.

23. Hamm CW, Möllmann H, Holzhey D, et al. The German aortic valve registry (GARY): in hospital outcome. Eur Heart J. 2014;35(24):1588-98.

24. Sabaté M, Cánovas S, García E, et al. Predictores de mortalidad hospitalaria y a medio plazo tras el reemplazo valvular aórtico transcatéter: datos del registro nacional TAVI 2010-2011. Cirugia Cardiovasc. 2013;20(4):174-83.

25. Green P, Arnold SV, Cohen DJ, et al. J. Relation of frailty to outcomes after Transcatheter aortic valve replacement (from the PARTNER trial). Am J Cardiol. 2015;116(2):264-9.

26. Huded CP, Huded JM, et al. Frailty status and outcomes following transcatheter aortic valve replacement. Am J Cardiol. 2016;117(12)1966-71.

27. Kleczynski P, Bagienski M, Dziewierz A, Rzeszutko L, Sorysz D, Trebacz J, Sobczynski R, Tomala M, Stapor M, Dudek D. Twelve month quality of life improvement and all cause mortality in elderly patients undergoing transcatheter aortic valve replacemten. Int J Artif Organs. 2016;39(8):444-9.

28. Ferrucci $L$, Hesdorffer C, Bandinelli $S$, et al. Frailty as a nexus between the biology of aging, environmental conditions and clinical geriatrics. Public Health Rev. 2011.
29. Yan TD, Cao C, Martens-Nielsen J, Padang R, Ng M, Vallely MP, et al. Transcatheter aortic valve implantation for high-risk patients with severe aortic stenosis: a systematic review. Thorac Cardiovasc Surg. 2010;139(6): 1519-28.20.

30. Grimard BH, Larson JM. Aortic stenosis: diagnosis and treatment. Am Fam Physician. 2017;78(6):717-24

\section{Publisher's Note}

Springer Nature remains neutral with regard to jurisdictional claims in published maps and institutional affiliations.
Ready to submit your research? Choose BMC and benefit from:

- fast, convenient online submission

- thorough peer review by experienced researchers in your field

- rapid publication on acceptance

- support for research data, including large and complex data types

- gold Open Access which fosters wider collaboration and increased citations

- maximum visibility for your research: over $100 \mathrm{M}$ website views per year

At BMC, research is always in progress.

Learn more biomedcentral.com/submissions 